\title{
Leukocyte and endothelial adhesion molecules in patients with hypercholesterolemia: the effect of atorvastatin treatment
}

\author{
T. ŠTULC ${ }^{1}$, M. VRABLÍK ${ }^{1}$, Z. KASALOVÁ ${ }^{1}$, I. MARINOV ${ }^{2}$, H. SVOBODOVÁ ${ }^{1}$, \\ R. С̌ESKA ${ }^{1}$
}

${ }^{1}$ Third Department of Internal Medicine, Charles University, First Faculty of Medicine, Prague and

${ }^{2}$ Institute of Hematology and Blood Transfusion, Prague, Czech Republic

Received October 2, 2006

Accepted February 12, 2007

On-line available April 25, 2007

\begin{abstract}
Summary
Atherogenesis involves the migration of leukocytes into vascular subendothelial space, a process mediated by endothelial and leukocyte cell adhesion molecules. Endothelial molecules are assessed indirectly via serum levels, but leukocyte molecules can be assessed directly. We have therefore hypothesized that leukocyte adhesion molecules are altered to a greater degree in hypercholesterolemia than serum endothelial adhesion molecules. We examined 29 subjects with hypercholesterolemia and 27 controls at baseline and after 12 weeks of atorvastatin treatment ( $20 \mathrm{mg} /$ day). Expression of leukocyte integrins CD1la, CD11b, CD18, and CD49d and of L-selectin was measured by flow cytometry. Serum ICAM-1, E-selectin and von Willebrand factor were measured by ELISA. Expression of leukocyte adhesion molecules was significantly higher in patients at baseline than in the controls, except for CD1la. Expression significantly decreased after atorvastatin in most adhesion molecules except for $\mathrm{CD} 11 \mathrm{~b}$. In contrast, there was no effect of hypercholesterolemia and/or atorvastatin on the serum endothelial molecules. Leukocyte but not endothelial adhesion molecules were influenced by hypercholesterolemia and by lipid lowering treatment. Leukocyte molecules may therefore be a more sensitive marker of atherogenesis than endothelial molecules. Our results support the role of increased leukocyte adhesiveness in atherogenesis.
\end{abstract}

\section{Key words}

Atherosclerosis - Cell adhesion molecules - Cholesterol • Endothelium • Leukocytes

\section{Corresponding author}

T. Štulc, Third Department of Internal Medicine, U Nemocnice 1, 12821 Prague 2, Czech Republic. Fax : +420-22491 9780. E-mail: tstulc@lf1.cuni.cz

\section{Introduction}

The infiltration of the subendothelial space with leukocytes plays an important role in atherogenesis. Leukocytes serve as precursors for the formation of foam cells, impair endothelial dysfunction and maintain the inflammatory infiltration of the plaque and influence myointimal proliferation (Huo and Ley 2001). Moreover, they also contribute to the development of acute atherothrombotic events: during later stages of plaque development they produce proteolytic enzymes, thus decreasing the mechanical stability of plaque and increasing the risk of plaques rupture (Galis and Khatri 2002).

The adhesion and transendothelial migration of leukocytes from blood into the subendothelial space is mediated by cell adhesion molecules, which are expressed on the surface of both leukocytes and endothelial cells (Meerschaert and Furie 1995, McGorisk and Treasure 1996, Krieglstein and Granger 2001, Hansson et al. 2002, Rosenfeld 2002). Various proatherogenic factors increase the expression of adhesion molecules by endothelial cells in vitro (Ragab et al. 1996, Huo and Ley 2001). It was assumed until recently that the transendothelial migration of leukocytes is regulated mainly by the expression of endothelial adhesion molecules. Increased serum concentrations of these molecules was also observed in persons with hyperlipidemia and other risk factors for atherosclerosis, and lipid lowering treatment resulted in their decrease (Kowalski et al. 2003). Changes observed in patients, however, are usually not very pronounced (Semaan et al. 
2000), probably due to the fact that serum concentrations of adhesion molecules are only an indirect measure of their endothelial expression.

Recent work suggests that modulation of the expression of leukocyte adhesion molecules independently and substantially contribute to the regulation of leukocyte transendothelial migration. Atherogenic lipoproteins upregulate the expression of these molecules both in vitro (Lehr et al. 1995, Ragab et al. 1996, Kawakami et al. 2002) and in clinical conditions (Serrano et al. 2001, Kassirer et al. 1999). Cholesterol reduction by pharmacological as well as nonpharmacological means was recently demonstrated to decrease monocyte integrin and lipopolysaccharide receptor expression and reduce leukocyte adhesion to the endothelium (Weber et al. 1997, Rovers et al. 1998, Serrano et al. 2001).

In contrast to endothelial cells, expression of adhesion molecules on leukocytes can be measured directly by examining peripheral blood leukocytes. Thus, leukocyte expression of adhesion molecules may be a more sensitive indicator of vessel wall inflammation than plasma concentrations of endothelial adhesion molecules. We therefore compared leukocyte and endothelial adhesion molecules in patients with severe isolated hypercholesterolemia and in healthy persons, and studied the effect of pharmacological lipid lowering in hypercholesterolemia.

\section{Methods}

\section{Subjects and study design}

Patients with primary hypercholesterolemia were included in the study. The subjects were over 18 years old, with serum total cholesterol $>7.0 \mathrm{mmol} / \mathrm{l}$ after 4 weeks of a lipid-lowering diet, without any lipidlowering medication. Patients with hypertriglyceridemia (triglycerides $>4.5 \mathrm{mmol} / \mathrm{l}$ ), secondary hyperlipidemia, manifest vascular disease, diabetes, malignancy or other major disease were excluded. The control group consisted of healthy subjects (with total cholesterol $<6.0 \mathrm{mmol} / 1$ and triglycerides $<2.0 \mathrm{mmol} / \mathrm{l})$ matched for age, sex, body mass index (BMI), and smoking status (Table 1).

Hypercholesterolemic patients were treated with atorvastatin $20 \mathrm{mg}$ once a day for 12 weeks. Clinical and laboratory examinations were performed at baseline and at the end of the treatment period. In the control group, only a baseline examination was performed. Blood for laboratory tests was withdrawn after an overnight fast.
Table 1. Baseline characteristics and serum levels of lipids and cell adhesion molecules of the study subjects.

\begin{tabular}{lccc}
\hline & $\begin{array}{c}\text { Control } \\
\text { subjects }\end{array}$ & $\begin{array}{c}\text { Patients } \\
\text { before } \\
\text { treatment }\end{array}$ & $\begin{array}{c}\text { Patients } \\
\text { after } \\
\text { treatment }\end{array}$ \\
\hline Number & 29 & 27 & \\
Male/female & $9 / 20$ & $8 / 19$ & \\
Age $($ years $)$ & $47.8 \pm 6.5$ & $52.3 \pm 11.5$ & \\
BMI $\left(\mathrm{kg} / \mathrm{m}^{2}\right)$ & $25.2 \pm 3.4$ & $26.7 \pm 4.3$ & \\
Hypertension & $6(21 \%)$ & $9(33 \%)$ & \\
Smoking & $5(17 \%)$ & $9(33 \%)$ & \\
TC $(\mathrm{mmol} / \mathrm{l})$ & $5.14 \pm 0.72$ & $8.59 \pm 1.60^{\mathrm{a}}$ & $5.87 \pm 1.12^{\mathrm{x}}$ \\
LDL-C $(\mathrm{mmol} / \mathrm{l})$ & $2.99 \pm 0.64$ & $6.20 \pm 1.39^{\mathrm{a}}$ & $3.67 \pm 0.94^{\mathrm{x}}$ \\
HDL-C $(\mathrm{mmol} / \mathrm{l})$ & $1.61 \pm 0.32$ & $1.63 \pm 0.32$ & $1.61 \pm 0.33$ \\
TG $(\mathrm{mmol} / \mathrm{l})$ & $1.21 \pm 0.66$ & $1.67 \pm 0.63^{\mathrm{b}}$ & $1.33 \pm 0.37^{\mathrm{y}}$ \\
ICAM-1 $(\mathrm{mg} / \mathrm{l})$ & $405 \pm 126$ & $479 \pm 136^{\mathrm{c}}$ & $495 \pm 136$ \\
E-selectin $[\mathrm{mg} / \mathrm{l})$ & $56.3 \pm 36.0$ & $58.5 \pm 38.3$ & $59.4 \pm 34.5$ \\
vWF $(\mathrm{U} / \mathrm{ml})$ & $0.99 \pm 0.89$ & $0.84 \pm 0.42$ & $0.99 \pm 0.47$ \\
\hline
\end{tabular}

BMI - body mass index, TC - total cholesterol, TG - triglycerides, HDL-C - HDL-cholesterol, LD-C - LDL-cholesterol, vWF - von Willebrand factor. Hypertension and smoking are presented as the number (percentage) of patients with the condition. ${ }^{a} \mathrm{P}<0.001,{ }^{b} \mathrm{P}<0.01,{ }^{c} \mathrm{P}<0.05$ patients vs. controls. ${ }^{x} \mathrm{P}<0.001$, ${ }^{\text {y }} \mathrm{P}<0.01$, ${ }^{\mathrm{z}} \mathrm{P}<0.05$ patients before vs. after treatment

All subjects signed an informed consent; the study protocol was approved by the Local Ethics Committee. The study conforms with the principles outlined in the Declaration of Helsinki.

\section{Measurement of leukocyte adhesion molecules}

We examined the expression of L-selectin (CD62L), $\alpha$-subunits of $\beta$-2 integrins LFA-1 (CD11a) and Mac-1 (CD11b), $\beta-1$ integrin VLA-4 (CD49d) and of the $\beta$-subunit of $\beta-2$ integrins (CD18). Measurements were performed within two hours of blood sampling. EDTA-anticoagulated blood was cooled down immediately after collection and kept at $4{ }^{\circ} \mathrm{C}$ until processing to avoid in vitro leukocyte activation.

The expression of adhesion molecules was measured by an immunofluorescence method using single-step staining with monoclonal antibodies. $100 \mu \mathrm{l}$ of whole blood were incubated for $15 \mathrm{~min}$ with the relevant antibody at room temperature, and then erythrocytes were lysed with $2 \mathrm{ml}$ of the FACS lysis solution (for $7 \mathrm{~min}$ ) with subsequent centrifugation and rinsing once with PBS. The fluorescence was quantified by flow cytometry (FACSCalibur, Becton-Dickinson, 


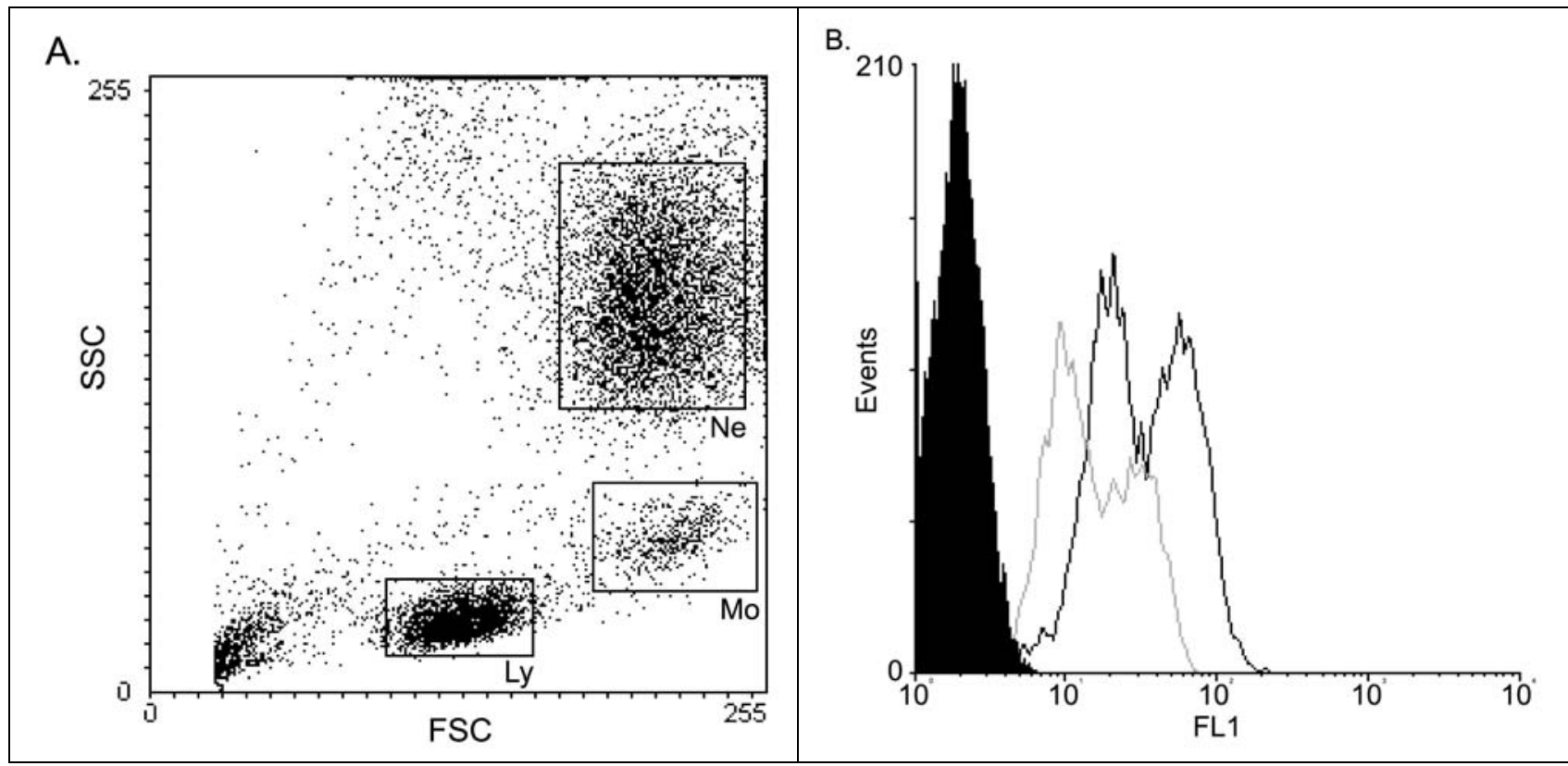

Fig. 1. Evaluation of leukocyte expression of cell adhesion molecules. The expression adhesion molecules was measured by flow cytometry, using a single-step staining with monoclonal antibodies. A. Lymphocytes (Ly), monocytes (Mo) and neutrophils (Ne) were identified based on their light scattering properties (forward scatter (FSC) vs. side scatter (SSC)). B. The specific fluorescence ( $F_{\text {spec }}$ ) was used as a measure of antigen expression, which was calculated as a difference between the total fluorescence of cells labeled with the relevant antibody $\left(\mathrm{F}_{\text {tot }}\right)$ and non-specific fluorescence of cells labeled with the control antibody $\left(\mathrm{F}_{\mathrm{bgd}}\right)$; the fluorescence is expressed in the arbitrary units. The example of CD18 expression in lymphocytes is shown in this figure; solid line - patient before treatment, dotted line - patient after treatment, filled area - control antibody-stained sample.

Mountain View, CA, USA); lymphocytes, monocytes and neutrophils were identified according to their lightscattering properties and were analyzed separately. Specific fluorescence was used as a measure of antigen expression, which was calculated as the difference between the fluorescence of cells labeled with the specific antibody and the non-specific fluorescence of cells labeled with the control antibody (Fig. 1). We used the following murine monoclonal antibodies, conjugated either with fluorescein isothiocyanate (FITC) or phycoerythrin (PE), for antigen detection: antiCD11a/FITC (clone MEM-25), anti-CD11b/FITC (clone CR3 Bear-1), anti-CD18/FITC (clone CLB-LFA-1/1) and anti-CD62L/PE (clone DREG-56), all from Caltag Laboratories, Burlingame, USA, and anti-CD49d/FITC (clone HP2/1) and non-specific control antibody (FITC and PE-labeled, clone 679.1Mc7) from Immunotech, Marseille, France. All the antibodies were of the $\mathrm{IgG} 1$ isotype.

\section{Other laboratory measurements}

Serum concentrations of endothelial adhesion molecules were measured by the enzyme immunoassay technique using commercially available kits; we examined intercellular adhesion molecule 1 (ICAM-1),
E-selectin (RD Systems, Abingdon, UK) and the von Willebrand factor (IMTEC Immunodiagnostik, Berlin, Germany). The sera for these measurements were kept at $-85{ }^{\circ} \mathrm{C}$ until analysis. Serum total cholesterol, triglyceride and high-density lipoprotein (HDL)cholesterol levels were measured using automated analyzer methods; low-density lipoprotein (LDL)cholesterol concentrations were calculated using the Friedewald formula. Biochemical markers of renal, liver and skeletal muscle function included serum transaminases, creatinine, creatine kinase and a full blood count.

\section{Statistics}

The results are expressed as a mean \pm S.D. For expression/concentration of adhesion molecules, the Mann-Whitney $U$ test was used to compare the differences between the controls and patients; Wilcoxon's paired test was used to compare the values before and after treatment. Differences in the remaining variables were tested by the two-sample or paired $t$ test as appropriate. Spearman correlation was used to test for the relationship between variables. All statistical tests are two-sided. 

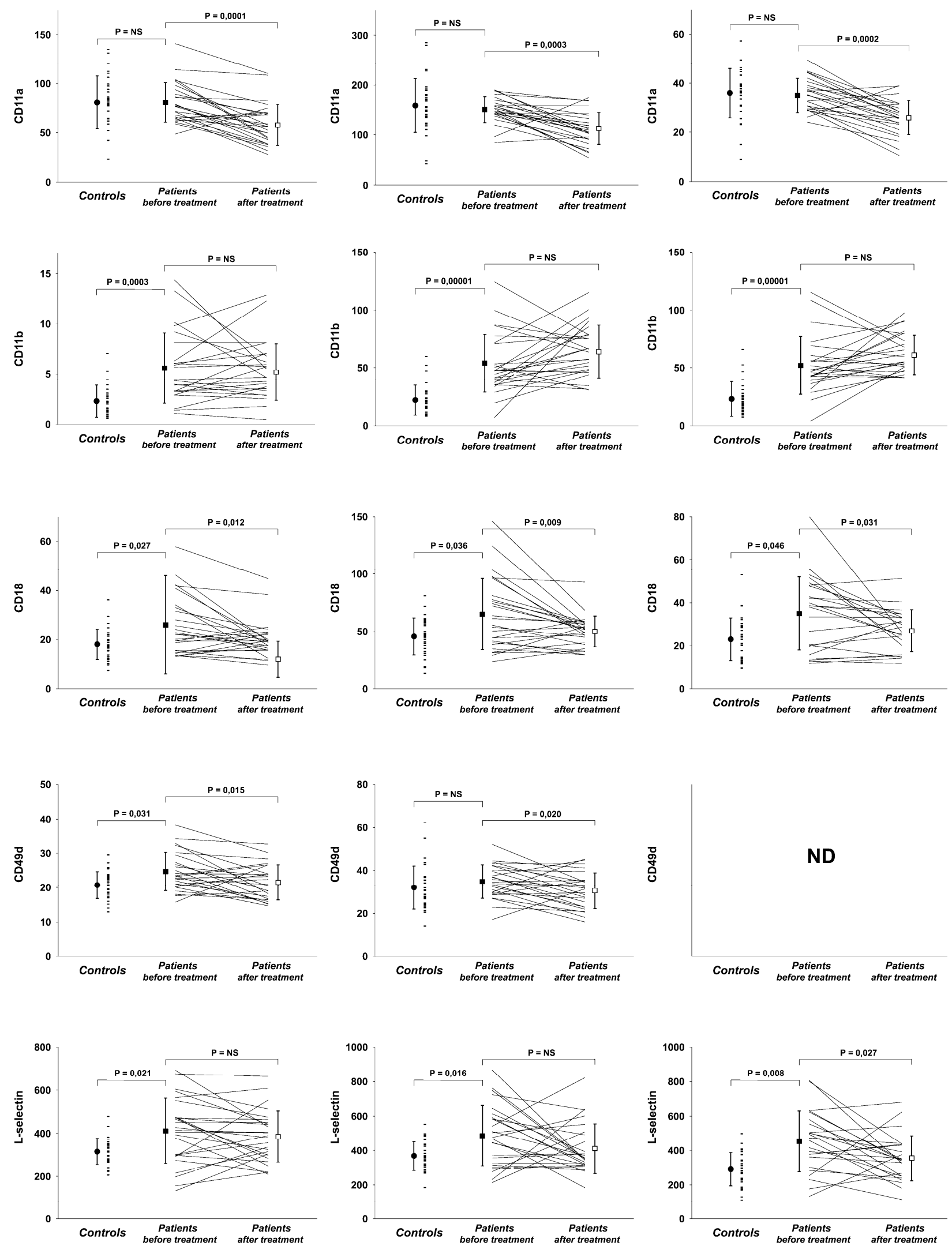

Fig. 2. Leukocyte expression of cell adhesion molecules in the studied subjects. Expression of cell adhesion molecules in lymphocytes (left column), monocytes (middle column) and neutrophils (right column) in healthy persons (circles) and in patients with hypercholesterolemia before (filled squares) and after 12 weeks of atorvastatin treatment (open squares). The results (in the arbitrary fluorescence units) are shown as mean \pm S.D. and as individual values. The expression of CD49d on monocytes was essentially not detectable (ND = non-detectable values); CD11b expression on lymphocytes was very low and the relevance of its measurement is thus limited. The significance levels are shown in the figures; NS - not significant. 


\section{Results}

Twenty-nine control subjects and 27 patients with hypercholesterolemia were included in the study; all patients completed the entire treatment period. The average follow-up time was $89 \pm 8$ days. The treatment was well tolerated; neither clinically manifest side effects nor significant change in safety laboratory parameters were noted throughout the study.

Baseline characteristics of the study groups are shown in Table 1. The groups were comparable with respect to age, sex, and body mass index. No difference in the incidence of hypertension or in smoking history was found.

Table 2. Leukocyte expression of cell adhesion molecules in the study subjects.

\begin{tabular}{ccc}
\hline $\begin{array}{c}\text { Control } \\
\text { subjects }\end{array}$ & $\begin{array}{c}\text { Patients } \\
\text { before } \\
\text { treatment }\end{array}$ & $\begin{array}{c}\text { Patients } \\
\text { after } \\
\text { treatment }\end{array}$ \\
\hline
\end{tabular}

\section{CD11a}

\begin{tabular}{|c|c|c|c|}
\hline Lymphocytes & $80.7 \pm 28.3$ & $80.8 \pm 20.7$ & $58.8 \pm 21.3^{x}$ \\
\hline Monocytes & $159 \pm 55$ & $151 \pm 26$ & $113 \pm 33^{x}$ \\
\hline Neutrophils & $36.2 \pm 10.3$ & $35.4 \pm 6.6$ & $26.0 \pm 7.3^{x}$ \\
\hline \multicolumn{4}{|l|}{$C D 11 b$} \\
\hline Lymphocytes & $2.33 \pm 1.58$ & $5.60 \pm 3.58^{a}$ & $5.42 \pm 2.95$ \\
\hline Monocytes & $21.8 \pm 13.3$ & $52.5 \pm 25.9^{\mathrm{a}}$ & $64.8 \pm 21.7$ \\
\hline Neutrophils & $23.2 \pm 13.6$ & $52.3 \pm 25.1^{\mathrm{a}}$ & $62.5 \pm 17.1$ \\
\hline \multicolumn{4}{|l|}{ CD18 } \\
\hline Lymphocytes & $18.1 \pm 6.2$ & $25.6 \pm 12.1^{\mathrm{c}}$ & $20.0 \pm 7.5^{z}$ \\
\hline Monocytes & $45.6 \pm 16.2$ & $65.0 \pm 31.4^{\mathrm{c}}$ & $50.2 \pm 13.6^{y}$ \\
\hline Neutrophils & $23.0 \pm 10.2$ & $35.4 \pm 17.7^{\mathrm{c}}$ & $27.6 \pm 9.6^{z}$ \\
\hline \multicolumn{4}{|l|}{$C D 49 d$} \\
\hline Lymphocytes & $20.7 \pm 4.0$ & $24.6 \pm 5.6^{c}$ & $21.5 \pm 5.1^{\mathrm{z}}$ \\
\hline Monocytes & $32.0 \pm 10.4$ & $34.8 \pm 7.8$ & $30.5 \pm 8.3^{z}$ \\
\hline \multicolumn{4}{|l|}{ L-selectin } \\
\hline Lymphocytes & $315 \pm 62$ & $411 \pm 153^{c}$ & $385 \pm 119^{z}$ \\
\hline Monocytes & $368 \pm 83$ & $488 \pm 179^{c}$ & $411 \pm 145$ \\
\hline Neutrophils & $291 \pm 96$ & $453 \pm 177^{b}$ & $354 \pm 134$ \\
\hline
\end{tabular}

Expression of cell adhesion molecules in lymphocytes, monocytes and neutrophils in healthy persons and in patients with hypercholesterolemia before and after 12 weeks of atorvastatin treatment. The results (in the arbitrary fluorescence units) are shown as mean \pm S.D. The expression of CD49d on monocytes was essentially not detectable and it is therefore not shown; CD11b expression on lymphocytes was very low and the relevance of its measurement is thus limited. a $P<0,001$, ${ }^{b} \mathrm{P}<0.01,{ }^{\mathrm{C}} \mathrm{P}<0.05$ patients vs, controls. ${ }^{\mathrm{x}} \mathrm{P}<0.001,{ }^{\mathrm{y}} \mathrm{P}<0.01$, $\mathrm{P}<0.05$ patients before vs. after treatment
Serum levels of total and LDL-cholesterol and of triglycerides were higher in the patients than in the controls (Table 1); all these parameters were significantly reduced by atorvastatin treatment. HDL-cholesterol levels were not different in patients and controls and no change was evident after the therapy.

The expression of leukocyte adhesion molecules in the studied subjects is shown in Table 2 and Figure 2. There was increased expression of L-selectin and of all the integrins except for CD11a in the patients compared to the controls. The difference was marginally significant for CD18 and it was not significant for CD49d on monocytes. The atorvastatin treatment resulted in a significant decrease of all the integrins except for CD11b; in the case of L-selectin, there was a significant decrease in neutrophils but not in lymphocytes and monocytes. The magnitude of the differences between patients and controls was similar in all leukocyte subpopulations (lymphocytes, monocytes and neutrophils); similar results were found for the changes in their expression after atorvastatin treatment. There were neither significant correlations between the expression of cell adhesion molecules and lipid levels nor between treatment-induced changes of lipid levels and of the expression of adhesion molecules. The white blood counts including differential counts were similar in patients and the controls and were not influenced by the treatment.

Serum ICAM-1 concentration was elevated in the patients; the E-selectin and von Willebrand factor concentrations were similar in both the patients and the controls. There were no significant changes in the levels of any of these molecules after atorvastatin treatment (Table 1).

\section{Discussion}

Our results demonstrate that the leukocyte expression of most cell adhesion molecules studied was greater in patients with hypercholesterolemia than in the controls. Twelve weeks of lipid lowering treatment with atorvastatin resulted in a decrease in leukocyte expression of adhesion molecules. Our results support the role of increased leukocyte adhesiveness in the development of atherosclerosis.

Factors affecting leukocyte adhesion to endothelial cells have been investigated in vitro; however, there are few data on the expression of leukocyte adhesion molecules under clinical conditions. The leukocyte recruitment into the subendothelial space 
depends on several groups of molecules. It is initiated by leukocyte rolling, which is mediated by loose interactions between selectins and their glycoprotein counterligands. During this interaction, integrins on the leukocyte surface become activated, and strong adhesion of leukocytes to the endothelial cells then becomes possible through the interaction between leukocyte integrins and endothelial ICAMs and vascular cell adhesion molecule-1. The final step is the leukocyte migration across the endothelium (Wautier et al. 1999, Serrano et al. 2001, Rosenfeld 2002). Most authors have studied a limited number of these molecules. In the present study, we examined L-selectin and several integrins, and provide a broader evaluation of leukocyte expression of adhesion molecules. In patients with hyperlipidemia and atherosclerosis, the $\mathrm{CD} 11 \mathrm{~b}$ molecule has most frequently been studied and an increased expression has been described in comparison with healthy controls (Mazzone et al. 1997, Kassirer et al. 1999, Serrano et al. 2001). However, this increase was only moderate (Weber et al. 1997) or even absent in some studies (de Bont et al. 1999). The effect of the lipid lowering treatment also varied from a considerable decrease of $\mathrm{CD} 11 \mathrm{~b}$ expression over a moderate decrease up to no effect at all. In addition to the $\mathrm{CD} 11 \mathrm{~b}$, an increased expression of integrins CD11a (Rezaie-Majd et al. 2003), CD18 (Rezaie-Majd et al. 2003) and CD49d (Uno et al. 1995) were described in patients with hyperlipidemia or atherosclerosis, which decreased after a lipid lowering treatment; decreased (Serrano et al. 2001) or normal (Kassirer et al. 1999) L-selectin expression has also been reported.

Thus, the available data on the leukocyte expression of cell adhesion molecules under clinical conditions are not consistent. The contradictory nature of some results is likely contributed to by methodological differences. Most authors examined isolated leukocytes (Uno et al. 1995, Weber et al. 1997, Rovers et al. 1998, Rezaie-Majd et al. 2003), whereas in some other reports whole blood was used (Mazzone et al. 1997, Kassirer et al. 1999, Serrano et al. 2001). Further potentially important differences in the methods employed concern the temperature of the sample storage and the processing and anticoagulants used for blood sampling. All these factors can affect the results of measurements. In vitro manipulation leads to leukocyte activation, which upregulates the expression of most adhesion molecules; however, in the case of L-selectin, the leukocyte activation results in cleaving of its molecules from the cell surface and thus decreases their expression (Serrano et al. 2001). The effect of in vitro manipulation is more pronounced at higher temperatures $\left(20\right.$ to $37^{\circ} \mathrm{C}$ ), whereas it is nearly absent at $4{ }^{\circ} \mathrm{C}$. A considerable activating factor for leukocytes is gradient centrifugation used in isolating leukocytes (Wautier et al. 1999). Also, $\mathrm{Ca}^{2+}$ ions are necessary for the activation of integrins, so that using EDTA as an anticoagulant (vs. e.g. heparin) suppresses this process. Therefore, results obtained with methods, which include leukocyte separation and use manipulations at room temperature, probably reflect a potential of leukocytes for stimulation rather than the actual level of the leukocyte activation in vivo. In our work we attempted to prevent the in vitro stimulation; thus, we assume that our results reflect the actual expression of cell adhesion molecules in the studied subjects.

When evaluating the leukocyte expression of integrins, it is also necessary to take into account the fact that the leukocyte adhesion to the endothelium depends not only on the integrin expression (i.e. number molecules on the cell surface), but also on conformational changes of these molecules, i.e. so-called activation. In some cases, the conformational changes of integrins can affect the leukocyte adhesiveness more substantially than the changes of their expression (Diamond and Springer 1993). This is in agreement with the report by Weber $e t$ al. (1997) that the decrease of leukocyte adhesiveness after statin treatment was more pronounced than the decrease of integrin expression.

In our study, we evaluated the expression of adhesion molecules on lymphocytes, monocytes and neutrophils separately; it is of interest that the results in these three leukocyte subpopulations were similar. The magnitude of the change in the expression of each adhesion molecule after the atorvastatin treatment was similar in all three leukocyte subpopulations. Similarly, the difference in expression between patients and controls was also similar in all leukocyte subpopulations for any molecule tested. In most studies published to date, only monocytes were examined (Uno et al. 1995, Weber et al. 1997, Rovers et al. 1998, Rezaie-Majd et al. 2003), obviously due to the fact that they are precursors for macrophages and foam cells and their role in atherogenesis therefore appears most straightforward. However, both lymphocytes and neutrophils contribute to atherogenesis. In advanced human plaques, T-cells constitute approximately 10 to $20 \%$ of the cell population, and they are often localized at the vulnerable, 
rupture-prone sites of the lesions (Jonasson et al. 1986, Van der Wal et al. 1994). Finally, blood neutrophils play a crucial role in ischemia-reperfusion injury, infiltrating the damaged tissue and causing microcirculatory dysfunction (Jordan et al. 1999). The importance of lymphocytes, monocytes as well as neutrophils for the development of atherosclerosis and of its complications is thus comparable. The mechanisms responsible for increased leukocyte adhesiveness in hypercholesterolemia are not yet fully understood, but they are likely to differ at least partially between various cell types. It is therefore somewhat surprising that these leukocyte subpopulations were similarly affected by hyperlipidemia and that they responded similarly to the lipid-lowering treatment.

In contrast to the leukocyte expression of adhesion molecules, there was only an irregular increase in serum concentrations of endothelial activation markers in patients with hyperlipidemia (increase of ICAM-1 only), and these markers were not influenced by the lipidlowering treatment. This observation is surprising because the regulatory role of endothelium for leukocyte recruitment into the sites of inflammation or injury has been demonstrated (McGorisk and Treasure 1996, Hansson et al. 2002), ICAM-1 and E-selectin playing a major role in this process (Krieglstein and Granger 2001, Meerschaert and Furie 1995, Huo and Ley 2001). The von Willebrand factor is a soluble protein produced by endothelial cells, which promotes platelet adhesion and aggregation (Folsom et al. 1997, Ruggeri and Ware 1992). Further experiments also demonstrated an increase in the expression of cell adhesion molecules by endothelial cells induced by atherogenic lipoproteins as well as a decrease in their expression after several lipidlowering agents (Yuan et al. 2001, Li et al. 2002). Direct examination of endothelial cells (in contrast to leukocytes) is, however, practically impossible in the clinical settings and therefore, the serum concentrations of endothelial molecules are used as an indirect marker of their endothelial expression. Increased concentrations of endothelial adhesion molecules and the von Willebrand factor in the blood were observed in persons with hyperlipidemia or with other risk factors for atherosclerosis, and the lipid-lowering treatment resulted in their decrease (Kowalski et al. 2003, Semaan et al. 2000, Folsom et al. 1997, Wang et al. 2004, Hernandez et al. 2003). Changes observed in patients, however, are typically not pronounced (Semaan et al. 2000, Hernandez et al. 2003, Kowalski et al. 2003), and in some studies, there have been no changes at all in the serum concentrations of cell adhesion molecules in subjects with hyperlipidemia (Sbarouni et al. 2000, Rosenson et al. 2004). A likely reason for this partial discrepancy between experimental and clinical observations is probably the fact, that the measurement of serum concentrations of adhesion molecules is not a very sensitive indicator of their endothelial expression.

The mechanism of the effect of statins on leukocyte adhesiveness has not been completely elucidated. One likely mechanism is the effect through cholesterol reduction. A decrease of leukocyte adhesion molecules was observed after cholesterol lowering by LDL-apheresis (Uno et al. 1995, Rovers et al. 1998), and in this case of non-pharmacological treatment, the effect on leukocytes cannot be explained in any other way than by a cholesterol decrease itself. Moreover, in our as well as in other studies the expression of adhesion molecules was increased in subjects with hypercholesterolemia. These observations support the direct association between CAM expression of adhesion molecules and lipid levels, which is probably mediated through scavenger receptors. However, statins may affect leukocyte function through other mechanisms, independent of lipid lowering. Statins had a direct effect on the in vitro expression of leukocyte adhesion molecules (Weber et al. 1997, Kawakami et al. 2002, Rezaie-Majd et al. 2003). This effect of statins may be mediated by the inhibition of intracellular isoprenoid mediators, with subsequent blocking of the nuclear factor- $\kappa \mathrm{B}$, interference with the signal pathway of Rho/Rho-kinase and affecting the cytoskeleton (Kawakami et al. 2002, Rodriguez-Fernandez et al. 2001). In addition, statins may affect leukocyte function through other indirect mechanisms, such as decreasing endothelial activation and reducing oxidative stress and susceptibility of LDL particles to oxidation; these effects may reduce stimulation of leukocytes by activated endothelium and by products of oxidative damage and thus reduce expression of adhesion molecules.

In clinical settings, it is difficult to separate these diverse effects of statins on leukocytes. Nevertheless, it may be of interest that in our study, the changes in the expression of adhesion molecules after the atorvastatin treatment did not correlate with changes in blood lipids; hence, CD11a expression decreased below the levels observed in controls. This might suggest that some lipidindependent mechanisms could have contributed to the effect of atorvastatin on leukocytes. It therefore appears likely that the effect of statins on leukocyte adhesiveness 
has both lipid lowering-dependent and independent components. This question requires further investigation.

\section{Conclusion}

In patients with hyperlipidemia, there was an increased leukocyte expression of most cell adhesion molecules studied, which was considerably decreased after the atorvastatin treatment. The question that arises is whether this novel effect on leukocyte function contributes to the antiatherogenic effect of atorvastatin. It is tempting to speculate that reducing leukocyte recruitment would reduce plaque inflammation, improve plaque stability and limit ischemia-induced injury. Future research is needed to clarify whether the effect on leukocytes contributes to the clinical benefits of statin treatment in patients at risk of atherosclerosis.

\section{Conflict of Interest}

There is no conflict of interest.

\section{Acknowledgements}

Supported by the Ministry of Education, Youth and Sports (MSMT) research project 0021620807.

\section{References}

DE BONT N, GEIJTENBEEK TB, NETEA MG, SMILDE TJ, DEMACKER PN, FIGDOR CG, VAN DER MEER JW, STALENHOEF AF: Integrin mediated adhesion of mononuclear cells from patients with familial hypercholesterolemia. Eur J Clin Invest 29: 749-757, 1999.

DIAMOND MS, SPRINGER TA: A subpopulation of MAC-1 (CD11b/CD18) molecules mediates neutrophil adhesion to ICAM-1 and fibrinogen. J Cell Biol 120: 545-556, 1993.

FOLSOM AR, WU KK, ROSAMOND WD, SHARRETT AR, CHAMBLESS LE: Prospective study of hemostatic factors and incidence of coronary heart disease: the atherosclerosis risk in communities (ARIC) study. Circulation 96: 1102-1108, 1997.

GALIS ZS, KHATRI JJ: Matrix metalloproteinases in vascular remodelling and atherogenesis. Circ Res 90: 251-262, 2002.

HANSSON GK, LIBBY P, SCHONBECK U, YAN ZQ: Innate and adaptive immunity in the pathogenesis of atherosclerosis. Circ Res 91: 281-291, 2002.

HERNANDEZ C, LECUBE A, BARBERA G, CHACON P, LIMA J, SIMO R: Effects of hypolipidemic treatment on serum markers of vascular inflammation in dyslipidemic men. Med Sci Monit 9: 114-119, 2003.

HUO Y, LEY K: Adhesion molecules and atherogenesis. Acta Physiol Scand 173: 35-43, 2001.

JONASSON L, HOLM J, SKALLI O, BONDJERS G, HANSSON GK: Regional accumulation of T-cells, macrophages, and smooth muscle cells in the human atherosclerotic plaque. Arteriosclerosis 6: 131-138, 1986.

JORDAN JE, ZHAO ZQ, JOHANSEN JV: The role of neutrophils in myocardial ischemia-reperfusion injury. Cardiovasc Res 43: 860-878, 1999.

KASSIRER M, ZELTSER D, PROCHOROV V, SCHOENMAN G, FRIMERMAN A, KEREN G, SHAPIRA I, MILLER H, ROTH A, ARBER N, ELDOR A, BERLINER S: Increased expression of the CD11b/CD18 antigen on the surface of peripheral white blood cells in patients with ischemic heart disease: Further evidence for smoldering inflammation in patients with atherosclerosis. Am Heart J 138: 555-559, 1999.

KAWAKAMI A, TANAKA A, NAKAJIMA K, SHIMOKADO K, YOSHIDA M: Atorvastatin attenuates remnant lipoprotein-induced monocyte adhesion to vascular endothelium under flow conditions. Circ Res 91: 263-271, 2002.

KOWALSKI J, OKOPIEN B, MADEJ A, ZIELINSKI M, BELOWSKI D, KALINA Z, HERMAN ZS: Effects of fenofibrate and simvastatin on plasma sICAM-1 and MCP-1 concentrations in patients with hyperlipoproteinemia. Int J Clin Pharmacol Ther 41: 241-247, 2003.

KRIEGLSTEIN CF, GRANGER DN: Adhesion molecules and their role in vascular disease. Am J Hypertens 14: 44S54S, 2001. 
LEHR HA, KROMBACH F, MUNZING S, BODLAJ R, GLAUBITT SI, SEIFFGE D, HUBNER C, VON ANDRIAN UH, MESSMER K: In vitro effects of oxidized low density lipoprotein on CD11b/CD18 and L-selectin presentation on neutrophils and monocytes with relevance for the in vivo situation. Am J Pathol 146: 218-227, 1995.

LI D, CHEN H, ROMEO F, SAWAMURA T, SALDEEN T, MEHTA JL: Statins modulate oxidized low-density lipoprotein-mediated adhesion molecule expression in human coronary artery endothelial cells: role of LOX-1. $J$ Pharmacol Exp Ther 302: 601-605, 2002.

MAZZONE A, DE SERVI S, MAZZUCCHELLI I, FOSSATI G, GRITTI D, CANALE C, CUSA C, RICEVUTI G: Increased expression of $\mathrm{CD} 11 \mathrm{~b} / \mathrm{CD} 18$ on phagocytes in ischemic disease: a bridge between inflammation and coagulation. Eur J Clin Invest 27: 648-652, 1997.

MCGORISK GM, TREASURE CB: Endothelial dysfunction in coronary heart disease. Curr Opin Cardiol 11: 341-350, 1996.

MEERSCHAERT JA, FURIE MB: The adhesion molecules used by monocytes for migration across endothelium include CD11a/CD18, CD11b/CD18, and VLA-4 no monocytes and ICA-1, VCAM-1, and other ligands on endothelium. J Immunol 154: 4099-4112, 1995.

RAGAB MS, SELVARAJ P, SGOUTAS DS: Oxidized lipoprotein(a) induces cell adhesion molecule MAC-1 (CD 11b) and enhances adhesion of the monocytic cell line U937 to cultured endothelial cells. Atherosclerosis 123: 103-113, 1996.

REZAIE-MAJD A, PRAGER GW, BUCEK RA, SCHERNTHANER GH, MACA T, KRESS HG, VALENT P, BINDER BR, MINAR E, BAGHESTANIAN M: Simvastatin reduces the expression of adhesion molecules in circulating monocytes from hypercholesterolemic patients. Arterioscler Thromb Vasc Biol 23: 397-403, 2003.

RODRIGUEZ-FERNANDEZ JL, SANCHEZ-MARTIN L, REY M, VINCENTE-MAZANARES M, NARUMIYA S, TEXIDO J, SANCHEZ-MADRID F, CABANAS C: Rho and Rho-associated kinase modulate the tyrosine kinase PYK2 in T-cells through regulation of the activity of the integrin LFA-1. J Biol Chem 276: 4051840527, 2001.

ROSENFELD ME: Leukocyte recruitment into developing atherosclerotic lesions. Arterioscler Thromb Vasc Biol 22: 361-363, 2002.

ROSENSON RS, WOLFF D, TANGNEY CC: Statins reduce oxidized low-density lipoprotein levels, but do not alter soluble intercellular cell-adhesion molecule-1 and vascular cell-adhesion molecule-1 levels in subjects with hypercholesterolemia. Clin Sci (Lond) 106: 215-217, 2004.

ROVERS C, NETEA MG, DE BONT N, DEMACKER PNM, JACOBS C, KULLBERG BJ, VAN DER MEER JWM, STALENHOEF AFH: LPS-induced cytokine production and expression of $\beta 2$-integrins and CD14 by peripheral blood mononuclear cells of patients with homozygous familial hypercholesterolemia. Atherosclerosis 141: 99-105, 1998.

RUGGERI ZM, WARE J: The structure and function of von Willebrand factor. Thromb Haemost 67: 594-599, 1992.

SBAROUNI E, KROUPIS C, KYRIAKIDES ZS, KONIAVITOU K, KREMASTINOS DT: Cell adhesion molecules in relation to simvastatin and hormone replacement therapy in coronary artery disease. Eur Heart J 21: 975-980, 2000.

SEMAAN HB, GURBEL PA, ANDERSON JL, MUHLESTEIN JB, CARLQUIST JF, HORNE BD, SEREBRUANY VL: Soluble VCAM-1 and E-selectin, but not ICAM-1 discriminate endothelial injury in patients with documented coronary artery disease. Cardiology 93: 7-10, 2000.

SERRANO CV JR, YOSHIDA VM, VENTURINELLI ML, D'AMICO E, MONTEIRO HP, RAMIRES JA, DA LUZ PL: Effect of simvastatin on monocyte adhesion molecule expression in patients with hypercholesterolemia. Atherosclerosis 157: 505-512, 2001.

UNO H, UEKI Y, MURASHIMA J, MIYAKE S, TOMINAGA Y, EGUCHI K, YANO K: Removal of LDL from plasma by adsorption reduces adhesion molecules on mononuclear cells in patients with arteriosclerotic obliterance. Atherosclerosis 116: 93-102, 1995. 
VAN DER WAL AC, BECKER AE, VAN DER LOOS CM, DAS PK: Site of intimal rupture or erosion of thrombosed coronary atherosclerotic plaques is characterized by an inflammatory process irrespective of the dominant plaque morphology. Circulation 89: 36-44, 1994.

WANG Y, BLESSING F, WALLI AK, UBERFUHR P, FRAUNBERGER P, SEIDEL D: Effects of heparin-mediated extracorporeal low-density lipoprotein precipitation beyond lowering proatherogenic lipoproteins: reduction of circulating proinflammatory and procoagulatory markers. Atherosclerosis 175: 145-150, 2004.

WAUTIER JL, SCHMID-SCHONBEIN GW, NASH GB: Measurement of leukocyte rheology in vascular disease: clinical rationale and methodology. Clin Hemorheol Microcirc 21: 7-24, 1999.

WEBER C, ERL W, WEBER KSC, WEBER PC: HMG-CoA reductase inhibitors decrease CD11b expression and CD11b-dependent adhesion of monocytes to endothelium and reduce increased adhesiveness of monocytes isolated from patients with hypercholesterolemia. J Am Coll Cardiol 30: 1212-1217, 1997.

YUAN Y, VERNA LK, WANG NP, LIAO HL, MA KS, WANG Y, ZHU Y, STEMERMAN MB: Cholesterol enrichment upregulates intercellular adhesion molecule-1 in human vascular endothelial cells. Biochim Biophys Acta 1534: 139-148, 2001. 